(c) 2011 Elsevier B.V. All rights reserved.

\title{
First evidence of a potential antibacterial activity involving a laccase-type enzyme of the phenoloxidase system in Pacific oyster Crassostrea gigas haemocytes
}

\author{
Andrea Luna-Acosta ${ }^{a,{ }^{*}}$, Denis Saulnier ${ }^{\mathrm{b}, 1}$, Mylène Pommier ${ }^{\mathrm{a}}$, Philippe Haffner $^{\mathrm{b}}$, Sophie De Decker ${ }^{\mathrm{b}}$, \\ Tristan Renault ${ }^{\mathrm{b}}$, Hélène Thomas-Guyon ${ }^{\mathrm{a}, \text { * }}$ \\ ${ }^{a}$ Littoral Environnement et Sociétés (LIENSs), UMR 6250, CNRS-Université de La Rochelle, 2 rue \\ Olympe de Gouges, F-17042 La Rochelle Cedex 01, France \\ ${ }^{\mathrm{b}}$ Laboratoire de Génétique et Pathologie, Ifremer, av. du Mus de Loup, 17390 La Tremblade, France \\ ${ }^{1}$ Present address: Laboratoire Biotechnologie et Qualité de la Perle, Centre Océanologique du \\ Pacifique, Ifremer, BP 7004, 98719 Taravao, French Polynesia
}

* Corresponding author: Andrea Luna-Acosta, fax: +33 (0)5 465076 63, email address : aluna1508@yahoo.com, Hélène Thomas-Guyon, email address : hthomas@univ-Ir.fr

\begin{abstract}
:
Phenoloxidases (POs) are a group of copper proteins including tyrosinase, catecholase and laccase. In several insects and crustaceans, antibacterial substances are produced through the PO cascade, participating in the direct killing of invading microorganisms. However, although POs are widely recognised as an integral part of the invertebrate immune defence system, experimental evidence is lacking that these properties are conserved in molluscs, and more particularly in the Pacific oyster Crassostrea gigas. In the present study, Vibrio splendidus LGP32 and Vibrio aestuarianus 02/041 growths were affected, after being treated with $C$. gigas haemocyte lysate supernatant (HLS), and either a common substrate of POs, L-3,4-dihydroxyphenylalanine (L-DOPA), to detect catecholasetype PO activity, or a specific substrate of laccase, $p$-phenylenediamine (PPD), to detect laccase-type PO activity. Interestingly, a higher bacterial growth inhibition was observed in the presence of PPD than in the presence of L-DOPA. These effects were suppressed when the specific PO inhibitor, phenylthiourea (PTU), was added to the medium. Results of the present study suggest, for the first time in a mollusc species, that antibacterial activities of HLS from C. gigas potentially involve POs, and more particularly laccase catalysed reactions.
\end{abstract}

\section{Highlights}

Bacterial growth inhibition was studied in two Vibrio oyster bacterial pathogens. Different Crassostrea gigas tissues, haemolymph fractions, and PO substrates, were tested. The inhibition occurred only in the presence of $C$. gigas HLS and PO substrates. Bacterial growth inhibition was suppressed with a PO inhibitor. Results suggest that HLS antibacterial activities involve laccasetype PO-catalysed reactions.

Keywords: Phenoloxidases; Antibacterial activity; Vibrio; Bivalve; Immunity 
Abbreviations: POs, phenoloxidases; HLS, haemocyte lysate supernatant; L-DOPA, L-3,4dihydroxyphenylalanine; PPD, p-phenylenediamine; PTU, 1-phenyl-2-thiourea; DETC, diethyldithiocarbamate; CTAB, cethyltrimethylammonium bromide; OD, optical density.

\section{Introduction}

The Pacific oyster Crassostrea gigas (Thunberg, 1753) is an ecologically and economically important species that dominates overall other molluscs with respect to global world distribution and aquaculture production [1]. However, massive summer mortalities of $C$. gigas have become a widespread concern in the world in recent decades [2-4]. Studies have shown a positive correlation between $C$. gigas summer mortalities and the presence of pathogens (e.g. bacteria or viruses), and suggest that this could be related to a weakening of immune defence mechanisms in the host that would be potentially affected by environmental factors [4, 5]. Among immune defence mechanisms, phenoloxidases (POs; EC 1.14.18.1) are a group of copper proteins including tyrosinase (EC 1.14.18.1), catecholase (EC 1.10.3.1) and laccase (EC 1.10.3.2), which are the rate limiting enzymes in melanisation [6, 7], and play an important role in immune defence mechanisms in invertebrates [8]. In these organisms, POs exist as an inactive form, proPO. Pathogen associated molecular patterns (PAMPs), such as peptidoglycans or lipopolysaccharides from bacteria, or $\beta$-1,3-glucans from fungi, are recognized by pattern-recognition receptors (PRRs). This will trigger the activation of a cascade of serine proteases that activates PO-activating enzymes (PPAs), and therefore, the conversion of the pro-enzyme proPO into PO [8].

The three types of POs can oxidise o-diphenols, such as L-3,4-dihydroxyphenylalanine (LDOPA; catecholase activity). However, among these three enzymes, only tyrosinases can hydroxylate monophenols, such as L-tyrosine (monophenoloxidase activity), and only laccases can oxidise $\mathrm{m}$ - and $\mathrm{p}$-diphenols, or aromatic compounds containing amine groups, such as p-phenylenediamine (PPD; laccase activity) $[9,10]$. Recently, POs, and more particularly catecholase and laccase, have been detected and identified in different tissues of C. gigas, i.e. the haemolymph, digestive gland, gills and mantle [11-14]. In addition, studies have shown that PO activity in C. gigas can be modulated by environmental factors, such as the presence of contaminants [15-17], and that the expression of a gene coding for a putative laccase in C. gigas can be modulated in the presence of hydrocarbons [18].

Different roles have been attributed to POs in bivalves [19-22], especially in haemolymphatic immune defence mechanisms [23, 24], and PO-generated reactive compounds are known to contribute to the destruction of microbial cells in several insects and crustaceans [25-27]. However, there is no direct experimental evidence indicating that POs in molluscs, and more particularly in $C$. gigas, conserve these properties and therefore, that they participate in immune defences against pathogen agents in this species. A better understanding of roles played by POs in C. gigas is needed to expand our knowledge on immune defence mechanisms in this organism, and therefore to a better understanding of the potential causes of summer mortality events.

The aims of this work were (i) to study the implication of PO activity(ies) on C. gigas immune defence system through antimicrobial assays and (ii) to identify which type(s) of PO activity(ies) is(are) implicated in this mechanism. For this purpose, different $C$. gigas tissues (i.e. digestive gland, gills and mantle) and haemolymph fractions (i.e. the acellular fraction [plasma] and the haemocyte lysate supernatant [HLS]), were analysed for their ability to inhibit in vitro the growth of oyster bacterial pathogens related to Vibrio splendidus and Vibrio aestuarianus. These bacterial pathogens were found to be associated to $C$. gigas summer mortality outbreaks in France [28]. Additionally, a common substrate of POs, LDOPA, used to detect catecholase activity, a specific substrate of laccase, PPD, used to detect laccase activity, and a specific inhibitor of POs, 1-phenyl-2-thiourea (PTU), used to inhibit all types of POs, were tested for identification of PO activities, particularly in the haemocyte lysate supernatant (HLS). 


\section{Materials and methods}

\subsection{Oysters}

Three-year-old Pacific oysters, C. gigas (mean \pm SD; weight: $75.5 \pm 8.7 \mathrm{~g}$; length: $9 \pm 3 \mathrm{~cm}$ ) were purchased during October-November 2008 from shellfish farms in Aytré (Charente Maritime, France), on the French Atlantic coast, and were processed immediately after their arrival in the laboratory.

\subsection{Preparation of oyster tissue extracts}

After opening the oyster shells by cutting off the adductor muscle, haemolymph $(0.5-1 \mathrm{ml})$ was withdrawn directly from the pericardial cavity, with a 1-ml syringe equipped with a needle $(0.9 \times 25 \mathrm{~mm})$, and haemolymphs from 10 oysters were pooled [15]. Haemolymph samples were centrifuged $\left(260 \mathrm{~g}, 10 \mathrm{~min}, 4^{\circ} \mathrm{C}\right)$ to separate the cellular fraction (i.e. haemocytes) from the acellular fraction (i.e. plasma) [12]. The digestive gland, gills and mantle from 10 oysters were dissected and pooled. The haemocytes, digestive gland, gills and mantle were homogenized at $4^{\circ} \mathrm{C}$ in Tris buffer $\left(0.1 \mathrm{M}\right.$ Tris $\mathrm{HCl}, 0.45 \mathrm{M} \mathrm{NaCl}, 26 \mathrm{mM} \mathrm{MgCl}_{2}$ and $10 \mathrm{mM}$ $\mathrm{CaCl}_{2}$ ) adjusted to $\mathrm{pH} 7\left(1 \mathrm{ml}\right.$ of buffer for the HLS, $1 \mathrm{ml} \cdot \mathrm{g}^{-1}$ of fresh weight for the digestive gland and mantle and $0.5 \mathrm{ml} . \mathrm{g}^{-1}$ of fresh weight for the gills). The digestive gland, gills and mantle were lysed using an Ultra-Turrax (T25 basic, IKA-WERKE) at $19000 \mathrm{rpm}$ for $30 \mathrm{sec}$ and a Thomas-Potter homogenizer (IKA-Labortechnik, clearance $0.13-0.18 \mathrm{~mm}$ ) at $200 \mathrm{rpm}$ for $1 \mathrm{~min}$, and centrifuged at $10000 \mathrm{~g}$ for $10 \mathrm{~min}$ at $4^{\circ} \mathrm{C}$. The resulting supernatants were collected. Haemocytes were lysed using Thomas-Potter homogenizer at $200 \mathrm{rpm}$ for $1 \mathrm{~min}$ and centrifuged at $10000 \mathrm{~g}$ for $10 \mathrm{~min}$ at $4^{\circ} \mathrm{C}$, and the supernatant was collected. The resulting digestive gland, gills, mantle, plasma and HLS samples were filtered at $0.22 \mu \mathrm{m}$ (Millipore membrane-Millipore Co., Bedford, MA, USA) to eliminate bacteria. Absence of bacterial development in filtered samples was tested by incubating the samples with Zobell medium and by measuring potential bacterial growth with a spectrophotometer at $620 \mathrm{~nm}$ wavelength during at least $7 \mathrm{~h}$ (data not shown). Aliquots $(100 \mu \mathrm{l})$ were stored at $-80^{\circ} \mathrm{C}$. Each aliquot was used only once.

\subsection{Chemicals}

PO substrates (dopamine, L-3,4-dihydroxyphenylalanine [L-DOPA]) and inhibitors (1-phenyl2-thiourea [PTU], diethyldithiocarbamate [DETC]), laccase substrate (p-phenylenediamine [PPD]) and inhibitor (cethyltrimethylammonium bromide [CTAB]), mushroom tyrosinase and Trametes versicolor laccase were purchased from Sigma (France).

\subsection{Bacterial strains and effect of L-DOPA and PPD-derived compounds on bacterial growth}

Virulent $V$. splendidus LGP32 strain $[4,29]$ and $V$. aestuarianus 02/041 strain [4] isolated in experimental cohabitation trials (Ifremer, La Tremblade, France) and from the Ifremer experimental hatchery at Argenton (Brittany, France), respectively, were used in antibacterial assays. Bacteria were grown at $25^{\circ} \mathrm{C}$ for $20 \mathrm{~h}$ in Marine Broth (Difco) under constant shaking until they reached the stationary phase of growth. The bacterial culture concentrations were evaluated spectrophotometrically at an OD of $620 \mathrm{~nm}$. Cells were centrifuged at $3200 \mathrm{~g}$ for $10 \mathrm{~min}$, the supernatant discarded and the resulting pellet resuspended in sterile artificial seawater to obtain an OD of 1 that corresponded to a concentration of $1-2.10^{9}$ colony forming units per $\mathrm{ml}$ for both bacterial strains. 
Concentrations given in the following protocol correspond to final concentrations in the medium reaction, before adding Marine Broth. Resuspended bacteria cells ( $5 \mu \mathrm{l}$ at OD of 1$)$ were separately added to $100 \mu \mathrm{l}$ of prepared oyster tissue extracts and $100 \mu \mathrm{l}$ of L-DOPA $(1.25 \mathrm{mM})$ or PPD solution $(1.50 \mathrm{mM})$. The same protocol was used with PTU (1 mM)-treated HLS $(100 \mu \mathrm{l})$. Two types of controls were performed either replacing substrates with $100 \mu \mathrm{l}$ of Tris buffer as sterility controls of samples or replacing samples with $100 \mu$ of Tris buffer to monitor the potential inhibitory effect of substrates on bacterial growth. After a 90 min incubation at $25^{\circ} \mathrm{C}$, the samples were secondly diluted in Marine Broth medium (Difco) by a 20-fold factor: they were incubated with $4 \mathrm{ml}$ of Marine Broth and grown at $25^{\circ} \mathrm{C}$ with constant shaking. Then, $A_{620 \mathrm{~nm}}$ readings were carried out at 1-2 $\mathrm{h}$ intervals for 3-7 $\mathrm{h}$. The different samples were maintained at $25^{\circ} \mathrm{C}$ in a rotor $(10 \mathrm{rpm})$ during all the experiment.

\subsection{Phenoloxidase assays}

Catecholase-type PO activity was measured spectrophotometrically by recording the formation of o-quinones, by using the method described previously [13]. For all conditions, assays were performed with three 10-oyster pools. Each pool was tested in triplicate wells. PO assays were conducted in 96-well microplates (Nunc, France). L-DOPA or PPD were used as substrates, at final concentrations of $10 \mathrm{mM}$ and $50 \mathrm{mM}$, respectively. L-DOPA (10 $\mathrm{mM})$ and PPD (50 $\mathrm{mM})$ were prepared just before being used in Tris buffer and methanol, respectively. At $25^{\circ} \mathrm{C}, 10 \mu \mathrm{l}$ of sample was incubated with $80 \mu \mathrm{l}$ of L-DOPA and $50 \mu \mathrm{l}$ of Tris buffer. Immediately after L-DOPA addition, PO-like activity was monitored during $4 \mathrm{~h}$ at 490 $\mathrm{nm}$, by using a VersaMax ${ }^{\mathrm{TM}}$ microplate reader (Molecular Devices). Because of solubility constraints, the protocol was slightly modified in the case of PPD: the sample was incubated with $7 \mu \mathrm{l}$ of PPD (50 mM diluted in methanol) and $123 \mu \mathrm{l}$ of buffer (no effect of methanol was observed on the enzymatic reactions). PO-like activity was monitored during $2 \mathrm{~h}$ at $420 \mathrm{~nm}$. Results were systematically corrected for non-enzymatic autoxidation of the substrate.

PO inhibition assay was performed by preincubating $10 \mu \mathrm{l}$ of PO inhibitor (prepared at various concentrations in Tris buffer) with $10 \mu \mathrm{l}$ of sample for 20 minutes, at $25^{\circ} \mathrm{C}$. Then, PO assay was carried out with L-DOPA or PPD. Assays were performed with three 10-oyster pools. Each pool was tested in triplicate wells. Enzymatic oxidation (in the presence of PO inhibitor) was systematically corrected for non-enzymatic autoxidation of the substrate (in the presence of PO inhibitor).

Specific activities (SA) were expressed in international units (IU) per mg of total protein. One $\mathrm{IU}$ is defined as the amount of enzyme that catalyzes the appearance of $1 \mu$ mole of product per min [30], using molar extinction coefficients of L-DOPA and PPD reaction products of $3600 \mathrm{M}^{-1} \mathrm{~cm}^{-1}$ [31] and $43160 \mathrm{M}^{-1} \mathrm{~cm}^{-1}[32,33]$ under these conditions, respectively. The protein concentration of oyster tissue extracts was determined by the slightly modified Lowry method, as described previously [34]. Serum albumin (Sigma-Aldrich, France) was used as standard.

\subsection{Statistical analysis}

All values are reported as mean \pm standard deviation (SD). Statistical analysis was carried out with STATISTICA 7.0. Values were tested for normality (Shapiro test) and homogeneity of variances (Bartlett test). For normal values, a nested ANOVA test was used to analyse the results, with condition as fixed factor, and pool as random factor. Pool was nested within each combination of condition [35]. When no significant differences were observed between pools and the null hypothesis $\left(\mathrm{H}_{0}\right.$ : no difference between conditions) was rejected, significant differences were tested using Tukey's HSD test. For non normal values, a Kruskal-Wallis test was carried out, followed by Dunn's multiple comparisons test [35]. Statistical significance was designed as being at the level of $p<0.05$. 


\section{Results}

\subsection{Effect of PO-generated reactive intermediates on the growth of $\mathrm{V}$. splendidus LGP32}

strain in the presence of L-DOPA and oyster tissue extracts

In a previous study, catecholase-type PO activity was detected in the haemolymph of $C$. gigas with L-DOPA and dopamine as substrates [13]. However, in the present study, dopamine displayed a toxic effect, while L-DOPA displayed no toxic effect on LGP32, when used alone at $1.25 \mathrm{mM}$ concentration (data not shown). Therefore, further studies were carried out with L-DOPA (1.25 mM).

When the digestive gland, gills, mantle and acellular fraction of the haemolymph were incubated with LGP32 strains, no spectrophotometric changes were noticed in the absence nor in the presence of L-DOPA at $620 \mathrm{~nm}$, the wavelength for bacterial growth determination (data not shown). Interestingly, while optical density measures were not reduced in the presence of the HLS alone (Fig. 1a), they were significantly reduced in the presence of HLS and L-DOPA (Fig. 1a), indicating that a bacterial growth inhibition occurred. This effect was statistically significant after 5 and $6 \mathrm{~h}$ of incubation in presence of Marine Broth. Since inhibitory effects were noticed only with HLS (and PO substrate), further studies were conducted with this oyster extract.

3.2. Effect of PO-generated reactive intermediates on the growth of $V$. aestuarianus in the presence of L-DOPA and HLS

In order to confirm results obtained with LGP32, the effect of L-DOPA and HLS on an oyster bacterial pathogen phylogenetically distinct from $V$. splendidus, i.e. $V$. aestuarianus 02/041, was tested. In the presence of L-DOPA, a significant 02/041 growth inhibition was observed after $6 \mathrm{~h}$ of incubation (Fig. 1b).

\subsection{Effect of PO-generated reactive intermediates on the growth of $V$. splendidus and}

\section{V. aestuarianus in the presence of PPD and HLS}

We decided next to test a PO substrate different from L-DOPA. In a previous study, laccasetype PO activity was detected in the haemolymph of $C$. gigas in the presence of the non phenolic substrate, PPD, but neither in the presence of the methoxy phenolic substrate, 4hydroxy-3,5-dimethoxybenzaldehyde azine (syringaldazine), nor in the presence of the non phenolic substrate, 2,2'-azino-bis(3-ethylbenzothiazoline-6-sulfonic acid) diammonium salt (ABTS) [13]. However, since PPD exerted an effect on bacterial growth in the absence of HLS in the present study (data not shown), results were expressed as the percentage of inhibition due to HLS (Table 1). Interestingly, when PPD was used as substrate, a later, but similar, inhibition of LGP32 and 02/041 growths than in the presence of L-DOPA (Fig. 1), was observed: $18 \pm 1$ and $29 \pm 1 \%$ of inhibition for LGP32 at 6 and $7 \mathrm{~h}$ and $30 \pm 6 \%$ of inhibition for $02 / 041$ at $7 \mathrm{~h}$ (Table 1$)$.

\subsection{Effect of PO inhibitors on PO-generated reactive intermediates}

In the absence of HLS, CTAB (0.5, 1 and $2 \mathrm{mM})$ and DETC $(1,3,5$ and $10 \mathrm{mM})$, but not PTU (1, 5 and $10 \mathrm{mM}$ ), exerted an inhibition on LGP32 bacterial growth (data not shown). 
Therefore, PO inhibitor effects were conducted only with the specific PO inhibitor, PTU. In the presence of PTU, the inhibition of LGP32 growth, produced in the presence of HLS and L-DOPA or PPD as substrates, was completely abolished, independently of the incubation time considered (Fig. 2a and b).

\subsection{PO activity in HLS and plasma}

Enzymatic tests were performed to quantify PO activity in two haemolymph fractions from $C$. gigas, i.e. the plasma and the HLS. Catecholase-type and laccase-type PO activities were detected in all samples with L-DOPA and PPD as substrates, and were inhibited in the presence of PTU (Table 2).

\section{Discussion}

The aim of the current work was (i) to study the implication of PO activity (ies) from C. gigas on immune oyster defence capacities, through antimicrobial assays, and (ii) to identify which type(s) of PO activity(ies) may be implicated on antibacterial activities. No oyster tissue (i.e. digestive gland, gills and mantle) or haemolymph fraction (i.e. plasma and HLS) exerted an antibacterial effect on $V$. splendidus LGP32 growth, in the absence of added PO substrates. Interestingly, in the presence of L-DOPA, only HLS inhibited bacterial growth. The higher PO activity detected in the HLS could contribute to the antibacterial properties observed in this haemolymph fraction, in comparison to the plasma (Table 2). Obviously, we were unable to estimate the substrate concentrations and enzyme activities required for an effective antimicrobial response against pathogens from the environment, but, among the different tissues (i.e. digestive gland, gills and mantle) and haemolymph fractions (i.e. plasma and HLS), haemocytes are known to play a critical role in bivalve defence responses [36, 37]. We may hypothesize that, in $C$. gigas, the PO activity in haemocytes is likely to restrict bacterial dissemination in vivo, and be complemented by other cellular immune reactions such as phagocytosis or encapsulation.

In the presence of L-DOPA, antibacterial effects on $V$. splendidus LGP32 and $V$. aesturianus 02/041 growth were observed (Fig. 1). Even if quinones formed with HLS alone or with HLS + L-DOPA could generate an optical signal at $620 \mathrm{~nm}$, the significant reduction in absorbance obtained at $620 \mathrm{~nm}$ with HLS + L-DOPA at times 5 and $6 \mathrm{~h}$ in Fig. 1a, and at $6 \mathrm{~h}$ in Fig. 1b, can only be interpretated as an inhibition of the bacterial growth. Additionally, results with both strains, belonging to phylogenetically distinct units, suggest that POgenerated reactive intermediates could exert an effect on different oyster pathogens. Previous studies reported that PO cascades may have not only antibacterial effects but also virucidal effects [38]. Therefore, the effect of HLS and PO substrates in the presence of other bacteria or viruses, pathogens for $C$. gigas, should be further investigated.

It is important to notice however that, in the present study, the inhibition of bacterial growth by HLS was reported only when L-DOPA or PPD were added to the reaction medium. These results differ from previous studies conducted in different invertebrate species, where HLS elicited an inhibitory effect on bacteria growth, and in the absence of PO substrates [36, 37, 39, 40]. Nonetheless, results from the present study are in agreement with studies carried out in insects and crustaceans, such as the tobacco hornworm Manduca sexta, the mealworm beetle Tenebrio molitor and the freshwater crayfish Pacifastacus leniusculus, where antibacterial substances produced by POs have been reported in in vitro experiments [25-27]. Additionally, this is the first time to our knowledge that antibacterial activities of HLS from a mollusc species have shown to potentially involve POs, comforting the hypothesis of Zhao et al. [25], who states that PO-catalysed formation of quinones and semiquinones is a universal defence mechanism to kill microbial pathogens. 
Results of the present study suggest also that natural PO substrate components have been inadvertently removed during HLS preparation, or alternatively, that they are in insufficient amount in bacterial culture medium to produce cytotoxic compounds. If we admit that, (1) as suggested by Cerenius et al. [27], some minutes are enough to obtain a bacteriotoxic effect from products generated by the phenoloxidase cascade (i.e. that the post-incubation dilution in the culture medium does not play a role in the bacteriotoxic effect), that, (2) as suggested by the present study, the prophenoloxidase cascade is essentially present in haemocytes, but that (3) the "natural" PO substrate is present in the acellular fraction of the haemolymph or in another tissue, we may hypothesize that the addition of an artificial substrate would be necessary to observe a bacteriotoxic effect with the HLS. Thus, it could be interesting to carry out the same type of experiments from the present study with plasma and HLS filtrated at $0.22 \mu \mathrm{m}$ (to get rid of commensal bacterial flora), or with haemolymph treated with antiobiotics and with pathogenic bacteria resistant to these antiobiotics (i.e. in order to keep haemocytes intact).

Since PO substrates may also be used by other enzymes such as peroxidases, the next step in our study consisted on verifying that the inhibition of bacteria growth observed with HLS, and L-DOPA or PPD as substrates, was due to a PO-like activity. For this, we followed LGP32 growth in the presence of HLS, PO substrates, and the specific inhibitor of PO, PTU. Antibacterial effects were inhibited in the presence of PTU. These results are in agreement with previous studies carried out in different invertebrate species where the antibacterial activity in the presence of PO substrates was inhibited by PTU [25, 27, 41]. Whether tyrosinase, catecholase or laccase are implicated in L-DOPA reactions remains unresolved. Recently, a gene encoding a laccase has been identified and characterized at a molecular level in C. gigas [GenBank accession EU678320; 42]. Moreover, previous studies suggest the absence of tyrosinase activity and the presence of laccase activity in haemocytes, suggesting that laccase could be implicated in the L-DOPA reactions observed in the present study [13]. Nevertheless, the inhibitory effect observed in the presence of the PO inhibitor, PTU, was transitional. This observation could be due to the method used to quantify bacterial concentrations. Indeed, the spectrophotometric method is a simple and rapid technique, i.e. not time consuming. However, this technique is not very sensitive, i.e. the quantification can only be carried out only at the end of the exponential growth phase but, during this phase, the inhibition of bacterial growth could be masked by an important proliferation of bacteria that would be resistant to the initial antibacterial treatment. Other non spectrophotometricalbased techniques such as RT-qPCR could be used in this type of studies to increase the sensitivity to detect living organisms at low concentrations. Furthermore, because of their high sensitivities, the RT-qPCR technique would allow to use low concentrated inocula, which will in turn increase the sensitivity of the antimicrobial test [43].

Antibacterial effects with PPD (1.50 mM) as substrate were higher than with L-DOPA (1.25 $\mathrm{mM}$ ) as substrate. This could be due to the fact that in PPD oxidation reactions, reactive semiquinones are produced while in L-DOPA oxidation reactions, quinones, which are more stable, are produced. Reactive semiquinones may react with $\mathrm{O}_{2}$ to yield a superoxide radical $\left(\mathrm{O}_{2}^{-}\right)$that may contribute to the production of other semiquinones or other oxygen radicals, that can be deleterious for Vibrio species [44]. In both cases, these results suggest that POcatalysed reactions are an integral component of $C$. gigas defence system involving the production of intermediates, e.g. quinones that kill invading microorganisms.

Roles of laccases have been described in plants, fungi, bacteria and insects [45-47]. However, this is the first time to the best of our knowledge that a laccase-type PO activity is shown to be implicated in immune defence mechanisms in a mollusc species. This can be related to the recent identification of a gene coding a multicopper oxidase/laccase in the Pacific oyster, C. gigas [42]. Nevertheless, many questions remain unresolved. For example, whether the intracellular activities represent actual intracellular laccases, extracellular laccases in the process of being exported, or a combination of the two, remains to be determined. Additionally, no activators of PO activity (e.g. trypsin, lipopolysaccharides, laminarin, zymosan) were used in the present study [12]. Therefore, further investigations are 
required on the role and mechanisms of action of laccases in invertebrates, and more particularly in molluscs of high economic value, such as C. gigas.

\section{Conclusion}

In summary, results in the presence of a specific chemical inhibitor of $\mathrm{PO}$ or of proPO activation, PTU, and of the enzyme substrates L-DOPA or PPD, suggest that a constitutive innate antibacterial immune response attributable to the activity of $P O$ is capable of limiting $V$. splendidus LGP32 and V. aestuarianus 02/041 infections in C. gigas, although this effect appears in our in vitro trial as transitional. Antibacterial effects could be due to products of the haemocyte enzyme PO cascade, including quinone, superoxide anion and hydrogen peroxide. Given the potentially important roles that these enzymes, in particular laccases, might play in bivalve immune defence mechanisms, more detailed investigation of their activities is clearly warranted.

\section{Aknowledgments}

This study was supported by a PhD grant from the Conseil Général of the Charente-Maritime for A. Luna-Acosta. The Conseil Régional de Poitou-Charentes is acknowledged for financial support through the research project 'POLERON' (Modifications chimiques de polluants organiques dans le bassin de Marennes-Oléron, toxicité des produits de dégradation sur l'huître creuse).

\section{References}

[1] FAO. Aquaculture Production: Quantities 1950-2008. In: Fishstat Plus, Rome; 2010, p. 457

[2] Cheney D, Macdonald E, Elston R. Summer mortality of Pacific oysters Crassostrea gigas (Thunberg): Initial findings on multiple environmental stressors in Puget Sound, Washington. J Shellfish Res 2000; 19:353-9.

[3] Huvet A, Herpin A, Dégremont L, Labreuche $Y$, Samain J, Cunningham C. The identification of genes from the oyster Crassostrea gigas that are differentially expressed in progeny exhibiting opposed susceptibility to summer mortality. Gene 2004; 343:211-20.

[4] Garnier M, Labreuche Y, Garcia C, Robert M, Nicolas J. Evidence for the involvement of pathogenic bacteria in summer mortalities of the Pacific oyster Crassostrea gigas. Microb Ecol 2007 ; 53 :187-96.

[5] Nicolas J, Renault T, Gagnaire B, Garcia C, Garnier M, Gay M, Labreuche Y, Le Roux F, Miossec L, Pepin J, Saulnier D. Les risques associés aux pathogènes. In: Samain J, McCombie $\mathrm{H}$, editors. Mortalité estivale de l'huître creuse Crassostrea gigas: Défi MOREST, 2007; p. 229-69.

[6] Sanchez-Ferrer A, Rodriguez-Lopez J, Garcia-Canovas F, Garcia-Carmona F. Tyrosinase: a comprehensive review of its mechanism. Biochim et Biophys Acta 1995; 1247:1-11.

[7] Chase M, Raina K, Bruno J, Sugumaran M. Purification, characterization and molecular cloning of prophenoloxidases from Sarcophaga bullata. Insect Biochem. Mol Biol 2000; 30: 953-67.

[8] Cerenius L, Lee B, Söderhäll K. The proPO-system: Pros and cons for its role in invertebrate immunity. Trends Immunol 2008; 29:263-71.

[9] Thurston C. The structure and function of fungal laccases. Soc Gen Microbiol 1994; 140:19. 
[10] Solomon E, Sunduran U, Machonkin T. Multicopper oxidases and oxygenases. Chem Rev 1996; 96:2563-606.

[11] Luna-Gonzalez A, Maeda-Martinez A, Vargas-Albores F, Ascencio-Vallea F, Miguel Robles-Mungaraya M. Phenoloxidase activity in larval and juvenile homogenates and adult plasma and haemocytes of bivalve molluscs. Fish Shell Immunol 2003; 15:275-82.

[12] Hellio C, Bado-Nilles A, Gagnaire B, Renault T, Thomas-Guyon H. Demonstration of a true phenoloxidase activity and activation of a ProPO cascade in Pacific oyster, Crassostrea gigas (Thunberg) in vitro. Fish Shell Immunol 2007; 22:433-40.

[13] Luna-Acosta A, Rosenfeld E, Amari M, Fruitier-Arnaudin I, Bustamante P, ThomasGuyon $\mathrm{H}$. First evidence of laccase activity in the Pacific oyster Crassostrea gigas. Fish Shell Immunol 2010; 28:719-26.

[14] Luna-Acosta A, Thomas-Guyon H, Amari M, Rosenfeld E, Bustamante P, FruitierArnaudin I. Differential tissue distribution and specificity of phenoloxidases from the Pacific oyster Crassostrea gigas. Comp Biochem Phys B 2011; 4:220-6.

[15] Gagnaire B, Thomas-Guyon H, Renault T. In vitro effects of cadmium and mercury on Pacific oyster, Crassostrea gigas (Thunberg), haemocytes. Fish Shell Immunol 2004; 16: 501-12.

[16] Bado-Nilles A, Gagnaire B, Thomas-Guyon H, Le Floch S, Renault T. Effects of 16 pure hydrocarbons and two oils on haemocyte and haemolymphatic parameters in the Pacific oyster, Crassostrea gigas (Thunberg). Toxicol In Vitro 2008; 22:1610-7.

[17] Luna-Acosta A, Bustamante P, Godefroy J, Fruitier-Arnaudin I, Thomas-Guyon H. Seasonal variation of pollution biomarkers to assess the impact on health status of juvenile Pacific oysters Crassostrea gigas exposed in situ. Env Sci Pol Res 2010; 17:999-1008.

[18] Bado-Nilles A, Renault T, Faury N, Le Floch S, Quentel C, Auffret M, Thomas-Guyon H. In vivo effects of LCO soluble fraction on immune-related functions and gene transcription in the Pacific oyster, Crassostrea gigas (Thunberg). Aquat Toxicol 2010; 97:196-203.

[19] Bailey K, Worboys B. The lamellibranch crystalline style. Biochem J 1960; 76:487-91.

[20] Paparo A, Aiello E. Cilio-inhibitory effects of branchial nerve stimulation in the mussel, Mytilus edulis. Comp Gen Pharmac 1970; 1:241-50.

[21] Malanga $C$, Young S. The metabolic fate of dopamine in the ciliated gill epithelium of bivalve molluscs. Comp Biochem Phys C 1978; 60:129-36.

[22] Zhang C, Xie L, Huang J, Chen K, Zhang R. A novel putative tyrosinase involved in periostracum formation from the pearl oyster (Pinctada fucata). Biochem Biophys Res Comm 2006; 342:632-9.

[23] Peters R, Raftos D. The role of phenoloxidase suppression in QX disease outbreaks among Sydney rock oysters (Saccostrea glomerata). Aquaculture 2003; 223:29-39.

[24] Jordan P, Deaton L. Characterization of phenoloxidase from Crassostrea virginica hemocytes and the effect of Perkinsus marinus on phenoloxidase activity in the hemolymph of Crassostrea virginica and Geukensia demissa. J Shellfish Res 2005; 24:477-82.

[25] Zhao P, Li J, Wang Y, Jiang H. Broad-spectrum antimicrobial activity of the reactive compounds generated in vitro by Manduca sexta phenoloxidase. Insect Biochem Mol Biol 2007; 37:952-9.

[26] Kan H, Kim C, Kwon H, Park J, Roh K, Lee H, Park B, Zhang R, Zhang J, Söderhäll K, $\mathrm{Ha} \mathrm{N}$, Lee B. Molecular control of phenoloxidase-induced melanin synthesis in an insect. J Biol Chem 2008; 283:25316-23.

[27] Cerenius L, Babu R, Söderhäll K, Jiravanichpaisal P. In vitro effects on bacterial growth of phenoloxidase reaction products. J Inv Pathol 2010; 103:21-3.

[28] Saulnier D, De Decker S, Haffner P, Cobret L, Robert M, Garcia C. A large-scale epidemiological study to identify bacteria pathogenic to Pacific oyster Crassostrea gigas and correlation between virulence and metalloprotease-like activity. Microb Ecol 2009; 59:787-98.

[29] Gay M, Renault T, Pons A, Le Roux F. Two Vibrio splendidus related strains collaborate to kill Crassostrea gigas: Taxonomy and host alterations. Dis Aquat Organ 2004; 62:65-74.

[30] Fenoll L, Rodriguez-Lopez J, Garcia-Molina F, Garcia-Canovas F, Tudela J. Unification for the expression of the monophenolase and diphenolase activities of tyrosinase. Int $U$ Biochem Mol Biol Life 2002; 54:137-41. 
[31] Rodriguez-Lopez JN, Tudela J, Varon R, Garcia-Carmona F, Garcia-Canovas F. Analysis of a kinetic model for melanin biosynthesis pathway. J Biol Chem, 1992;267:380110.

[32] Eggert,C, Temp U, Eriksson K. The lignolytic system of the white rot fungus Pycnoporus cinnabarinus: Purification and characterization of the laccase. App Env Microbiol 1996; 62:1151-8.

[33] Paranjpe $\mathrm{P}$, Karve M, Padhye S. Characterization of tyrosinase and accompanying laccase from Amorphophallus campanulatus. Indian J Biochem Biophys 2003; 40:40-5.

[34] Smith P, Khron R, Hermanson G, Mallia A, Gartner F, Provanzano M, Fujimoto E, Goeke N, Olson B, Klenk, D. Measurement of a protein using bicinchoninic acid. Anal Biochem 1985; 150:76-85.

[35] Zar J. Biostatistical analysis. Prentice-Hall, New Jersey. 1984; p. 718

[36] Rowley A, Brookman J, Ratcliffe N. Possible involvement of the prophenoloxidase system of the locust, Locusta migratoria, in antimicrobial activity. J Invert Path 1990; 56:31-8.

[37] Cheng TC. Bivalves. In: Ratcliffe NA, Rowley AF, editors. Invertebrate Blood Cells 1, Academic Press, London, 1981; p. 233-300.

[38] Shelby K, Popham H. Plasma phenoloxidase of the larval tobacco budworm, Heliothis virescens, is virucidal. J Insect Sci 2006; 13:1-12.

[39] Chisholm J, Smith V. Comparison of antibacterial activity in the hemocytes of different crustaceans species. Comp Biochem Phys A 1995; 110:39-45.

[40] Söderhäll K, Cerenius L. Role of prophenoloxidase-activating system in invertebrate immunity. Curr Opin Immunol 1998; 10:23-8.

[41] Li G, Zhang S, Li H. Ultrastructural localization and antibacterial activity of phenoloxidase in amphioxus Branchiostoma belcheri tsingtauense. J Marine Biol Assoc United Kingdom 2001; 81:705-6.

[42] Renault T, Faury N, Barbosa-Solomieu V, Moreau K. Suppression substractive hybridisation (SSH) and real time PCR reveal differential gene expression in the Pacific cupped oyster, Crassostrea gigas, challenged with Ostreid herpesvirus 1. Dev Comp Immunol 2011; 5:725-35.

[43] Saulnier D, De Decker S, Haffner P. Real-time PCR assay for rapid detection and quantification of Vibrio aestuarianus in oyster and seawater: A useful tool for epidemiological studies. J Microbiol Methods 2009; 77:191-7.

[44] Guillen F, Martinez M, Munoz C, Martinez A. Quinone redox cycling in the ligninolytic fungus Pleurotus eryngii leading to extracellular production of superoxide anion radical. Arch Biochem Biophys 1996; 339:190-9.

[45] Dittmer N, Suderman R, Jiang $H$, Zhu $Y$, Gorman M, Kramer K, Kanost $M$. Characterization of cDNAs encoding putative laccase-like multicopper oxidases and developmental expression in the tobacco hornworm, Manduca sexta, and the malaria mosquito, Anopheles gambiae. Insect Biochem Mol Biol 2004; 34:29-41.

[46] Burke R, Cairney J. Laccases and other polyphenol oxidases in ecto- and ericoid mycorrhizal fungi. Mycorrhiza 2002; 12:105-16.

[47] Mayer A. Polyphenol oxidases in plants - recent progress. Phytochemistry. 1987; 26:1120. 
Figure 1 Effect of HLS on V. splendidus LGP32 (a) and V. aestuarianus 02/041 (b) growth, with or without L-DOPA $(1.25 \mathrm{mM})$. Absorbance readings were taken from the cultures at different intervals and plotted against time. Mean $\pm S D A_{620 n m}, n=9$ (3 replicates of 3 pools of 10 oysters), $\mathrm{N}=3$ experiment replicates. ${ }^{*}=$ statistical difference for $\mathrm{p}<0.05$ between 'LGP32' and 'LGP32+HLS+L-DOPA', or between '02/041' and '02/041+HLS+LDOPA' conditions.

a

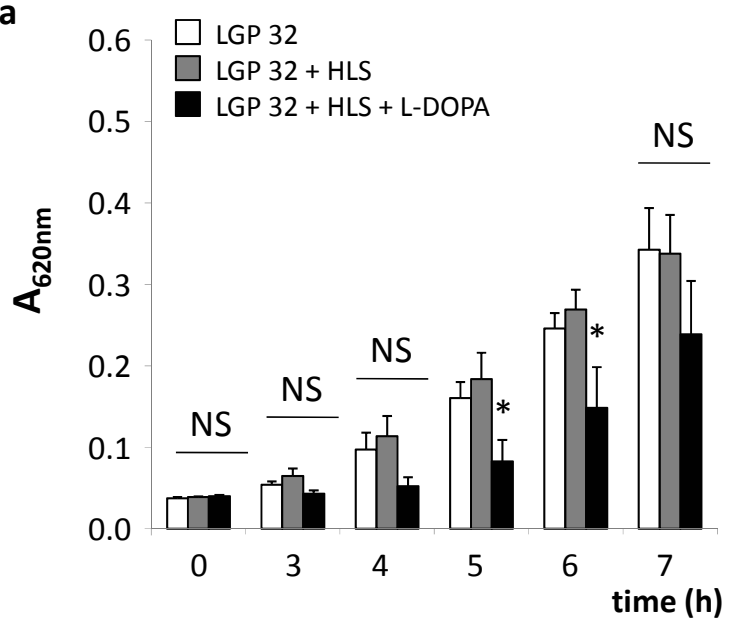

b

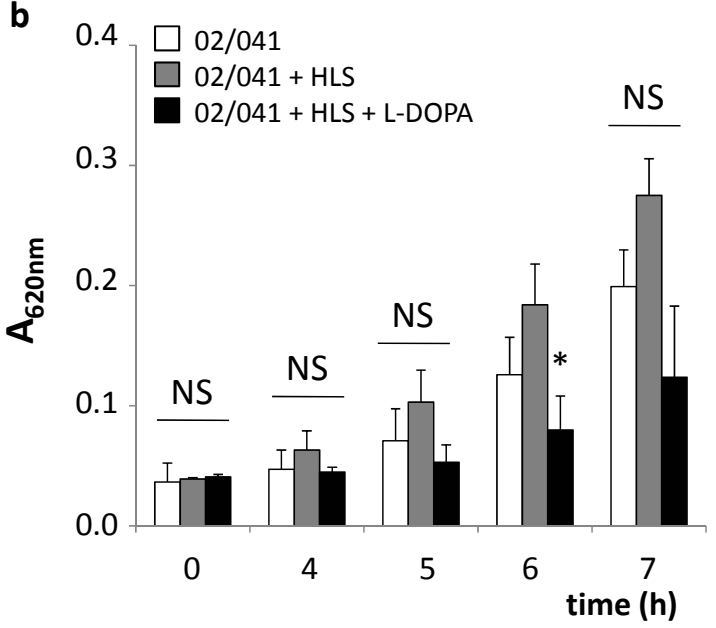


Figure 2 Effect of HLS and the specific PO inhibitor, PTU (1 mM), on V. splendidus LGP32 growth, with $1.25 \mathrm{mM}$ L-DOPA (a) or with $1.50 \mathrm{mM}$ PPD (b) as substrates. Absorbance readings were taken from the cultures at different intervals and plotted against time. Mean \pm SD $A_{620 n m}, n=9$ (3 replicates of 3 pools of 10 oysters), $N=3$ experiment replicates. * $=$ statistical difference for $\mathrm{p}<0.05$ between 'LGP32+HLS+substrate' and 'LGP32+HLS+substrate+PTU'.

a

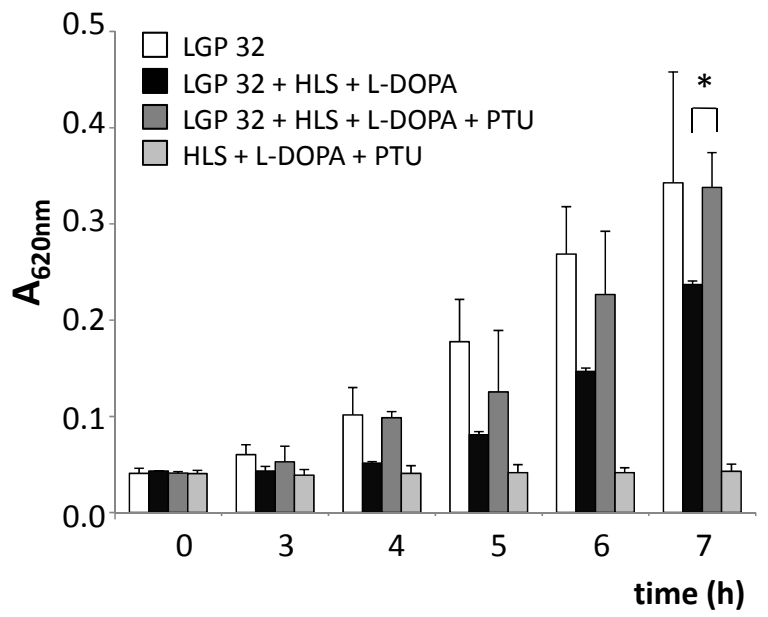

b

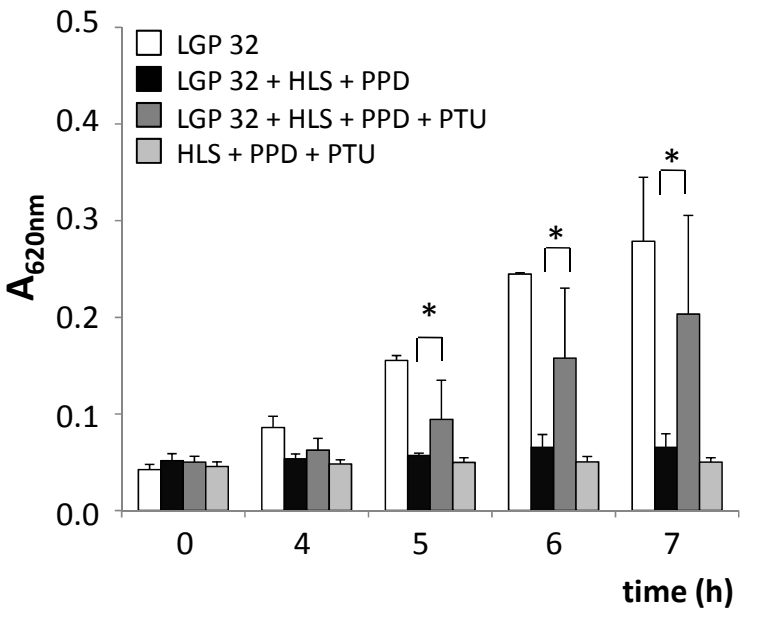


Table 1 Effect of PO-generated reactive intermediates on V. splendidus LGP32 and V. aestuarianus 02/041 growth, with PPD (1.50 mM) as substrate. Inhibition due to HLS (in \%) corresponded to: 11 - (absorbance 'bacteria + sample + substrate' / absorbance 'bacteria + substrate') $]^{\star} 100$. Mean $\pm S D, n=9, *=$ statistical difference $(p<0.05)$ between the conditions 'bacteria + sample + substrate' and 'bacteria + substrate'. Negative values correspond to bacterial growth stimulation.

\begin{tabular}{|c|c|c|c|c|c|}
\hline Treatments & 3 & 4 & 5 & 6 & 7 \\
\hline LGP32 + HLS + PPD (1.50 mM) & $-15 \pm 9$ & $-14 \pm 3$ & $-2 \pm 14$ & $18 \pm 1$ * & $29 \pm 1$ * \\
\hline 02/041 + HLS + PPD (1.50 mM) & $-22 \pm 2$ & $-17 \pm 6$ & $-14 \pm 6$ & $4 \pm 6$ & $30 \pm 6$ * \\
\hline
\end{tabular}


Table 2 Catecholase- and laccase-type phenoloxidase specific activities (in $\mu \mathrm{mol} . \mathrm{min}^{-1} \cdot \mathrm{mg}$ prot $^{-1}$ ) in haemocyte lysate supernatant (HLS) and plasma, by using L-DOPA (10 mM) and PPD (50 mM) as substrate and PTU (5 mM) as inhibitor. Values represent the average of three replicates \pm SD $(n=9)$, * = statistical difference $(p<0.05)$ between the conditions 'sample + substrate' and 'sample + substrate + PTU'.

\begin{tabular}{|l|c|c|}
\hline \multicolumn{1}{|c|}{ Sample } & L-DOPA $(10 \mathrm{mM})$ & PPD $(50 \mathrm{mM})$ \\
\hline HLS & $285.24 \pm 41.53$ & $164.68 \pm 50.44$ \\
\hline HLS + PTU $(5 \mathrm{mM})$ & $96.17 \pm 5.54^{*}$ & $0.00 \pm 32.45^{*}$ \\
\hline Plasma & $48.96 \pm 10.57$ & $5.05 \pm 1.25$ \\
\hline $\begin{array}{l}\text { Plasma + PTU (5 } \\
\mathrm{mM})\end{array}$ & $11.08 \pm 9.64 *$ & $0.00 \pm 4.05^{*}$ \\
\hline
\end{tabular}

